\title{
Effect of Exchangeable Cation in Clays on the Yield and Quality of the Bio-Oil during Microwave Pyrolysis of Cellulose
}

\author{
Alisa Doroshenko ${ }^{1}{ }^{(0)}$, Ihor Pylypenko ${ }^{2}$, Simona Gromovaite ${ }^{3}$, James Clark ${ }^{1, *}$ and \\ Vitaliy Budarin ${ }^{1}$ * \\ 1 Green Chemistry Centre of Excellence, The University of York, Heslington, York YO10 5DD, UK; \\ asd.kpi1@gmail.com \\ 2 The National Technical University of Ukraine "Igor Sikorsky Kyiv Polytechnic Institute", Peremohy Ave, \\ 37, 03056 Kyiv, Ukraine; i.pylypenko@kpi.ua \\ 3 College of Science and Engineering, The University of Edinburgh, 10 Max Born Crescent, \\ Edinburgh EH9 3BF, UK; s1708820@ed.ac.uk \\ * Correspondence: james.clark@york.ac.uk (J.C.); vitaliy.budarin@york.ac.uk (V.B.)
}

Received: 28 October 2020; Accepted: 1 December 2020; Published: 4 December 2020

\begin{abstract}
Bio-oil (pyrolysis oil) is an essential feedstock for the production of renewable fossil-free fuels and valuable chemicals. Enhancement of the pyrolysis oil yield and its quality are significant challenges for an efficient and sustainable biorefinery. Here, we report the microwave (MW)-assisted noncatalytic pyrolysis of cellulose, as a green and controllable alternative to conventional heating, in the presence of eco-friendly Li-, Na-, $\mathrm{K}-, \mathrm{Mg}-, \mathrm{Ca}-$ and Ba-bentonites. The detailed analysis of the MV heating traces demonstrates that the bentonite MW activity significantly depends on the presence of internal water. The intensity of this interaction is controlled by the cation nature reduced in the order: $\mathrm{Li}^{+}>\mathrm{Na}^{+}>\mathrm{K}^{+}$and $\mathrm{Mg}^{2+}>\mathrm{Ca}^{2+}>\mathrm{Ba}^{2+}$. A unique experimental design for the MW-assisted pyrolysis of cellulose in the presence of Li-doped clays helps to increase the bio-oil yield to $37.8 \%$ with high selectivity towards the commercially useful levoglucosan (purity: $39.36 \%$ ). The combination of an alternative green heating method and environmentally friendly bentonites can be used many times without recycling. We believe that the improved yields of bio-oil are due to: (i) high MW activity of bentonites, which conventionally increases the heating rates of cellulose; and (ii) production of water by hydrophilic clay minerals, favouring depolymerisation of cellulose.
\end{abstract}

Keywords: green; microwave; cellulose pyrolysis; bentonite; clay; exchangeable cation; bio-oil

\section{Introduction}

Bio-oil is a complex mixture of organic chemicals obtained through the pyrolysis of biomass. It represents an attractive source for the production of sustainable fuels and renewable chemicals [1]. Bio-oil catalytical upgrading for the production of valuable chemicals has been widely reported [2-4]. One of the ways of direct application of bio-oil as fuels was reported by the Huber group. They suggested the conversion of pyrolysis oils into industrial commodity chemical feedstocks using an integrated catalytic approach that combines hydroprocessing with zeolite-based catalysis [5]. The efficiency and sustainability of these methods depend on their yield and selectivity. A technique on the selective production of a large amount of high-value chemicals can substantially contribute to the development of a sustainable large-scale biorefinery.

There are many methods of enhancement of pyrolysis oil yield. The most well-known approach is adjusting the heating rate [6]. Biomass pretreatment is another critical parameter determining bio-oil yields. A substantial work by Bridgwater highlighted the influence of the feed drying, particle size, 
reactor configuration, heat transfer and supply, vapour residence time, secondary cracking, char and ash separations and ways for liquids collection [6]. Alternatively, Canadian researchers reported enhanced production of bio-oil together with its quality improvement using fast pyrolysis and fractional condensation concepts [7]. Other reported methods involve various high-energy influence on biomass, such as ball milling [8] or ultrasonic milling $[9,10]$.

On the other hand, an application of alternative types of heating, including microwave (MW)-assisted pyrolysis, is known to improve the yield of bio-oil and its quality [1,11]. During the biomass pyrolysis, produced gases and volatiles do not interact with MW irradiation due to their low density. This phenomenon substantially reduces the number of secondary processes, and therefore, the probability of unexpectable pressure increases. This is one of the essential advantages of MW heating. Furthermore, MW heating has instantaneous control and can be immediately switched-off in case of any technological problem. Moreover, MW-assisted pyrolysis is widely considered to be a green and sustainable method, which is capable of selective activation of the biomass constituents at more than $\sim 100^{\circ} \mathrm{C}$ lower than conventional methods [12-14]. Some of the most important disadvantages of MW technology are the high cost of equipment and the small depth of penetration of MW irradiation. Additionally, MW heating of biomass sometimes is problematic due to its weak interaction with biopolymers in the temperature range below their softening $[13,15]$. Such low-efficiency interaction usually results in lower yields of MW pyrolysis oil compared to those of conventional fast pyrolysis and, therefore, reduces the efficiency and sustainability of the production of valuable chemicals [1].

The enhancement of bio-oil yield during MW-assisted pyrolysis is a challenge for a sustainable biorefinery. This process is complicated and depends on both the same variables noted for the conventional approach and a few extra-parameters, such as samples density and mass, MW power, and many others [16].

In our previous publication, we have shown that clay minerals, which are widely used for water treatment $[17,18]$, can be excellent absorbers of MWs, demonstrating high values of maximum heating rate [1]. MW-assisted pyrolysis of cellulose mixed with bentonite resulted in $25 \mathrm{wt} . \%$ enhancement of bio-oil. This improvement happened due to both increased MW heating rates and internal water content in the presence of bentonite at high temperatures. The dehydration of clay mineral leads to the production of water which favours cellulose depolymerisation, simultaneously improving pyrolysis oil yield. According to our knowledge, the influence of clay structure on the MW-clay interaction mechanism has not been investigated. One of the ways to change the clay structure is an alternation of the exchangeable cation nature [19]. Therefore, the efficiency of the combined application of MW irradiation and clay in the biomass pyrolysis could be potentially improved using various clays with different exchangeable cations, taking care of the bio-oil quality and quantity.

The aim of the current paper is the optimization of yields of bio-oil during the MW-assisted pyrolysis of cellulose (as model biomass) using bentonite with various exchangeable ions. We decided to investigate the MW behaviour of bentonite with monovalent $\left(\mathrm{Li}^{+}, \mathrm{Na}^{+}\right.$and $\left.\mathrm{K}^{+}\right)$and divalent $\left(\mathrm{Mg}^{2+}\right.$, $\mathrm{Ca}^{2+}$ and $\mathrm{Ba}^{2+}$ ) exchangeable ions.

\section{Results and Discussion}

Detailed information about materials and methods is provided in Appendix A.

The original bentonite was characterised using various methods. The $X$-ray technique showed a basal spacing of $15.20 \AA$, which is typical for bentonite clay minerals (Figure S1A) [20]. Simultaneous thermal analysis (STA) revealed the presence of $8.4 \mathrm{wt} . \%$ of physisorbed water, while a total mass loss was $10.5 \mathrm{wt} . \%$ at $500{ }^{\circ} \mathrm{C}$ (Figure S1B). Such a high water content is due to the hydrophilic nature of the bentonite surface [21]. The affinity of a clay mineral for water is an essential parameter for a successful cation-exchange procedure in an aqueous solution of the salt.

A comparison between MW and conventional thermal behaviour of the set of $\mathrm{Li}^{-}, \mathrm{Na}^{-}, \mathrm{K}^{-}, \mathrm{Mg}^{-}$, $\mathrm{Ca}^{-}$and Ba-bentonites is given in Figure 1. The MW activity of the bentonite highly depended on the type of exchangeable cation. The MW traces (heating rate vs. temperature) are displayed in Figure 1A,B 
for the monovalent and divalent exchangeable cations, respectively. The heating rates below $\sim 110{ }^{\circ} \mathrm{C}$ (Figure 1A,B, green zones) were possibly associated with the physisorbed water, which is a well-known MW absorber. Some authors have reported the application of MW technology for drying of clay minerals, proving the $\mathrm{MW}$ activity of clays at $\mathrm{T}<110^{\circ} \mathrm{C}[22,23]$.
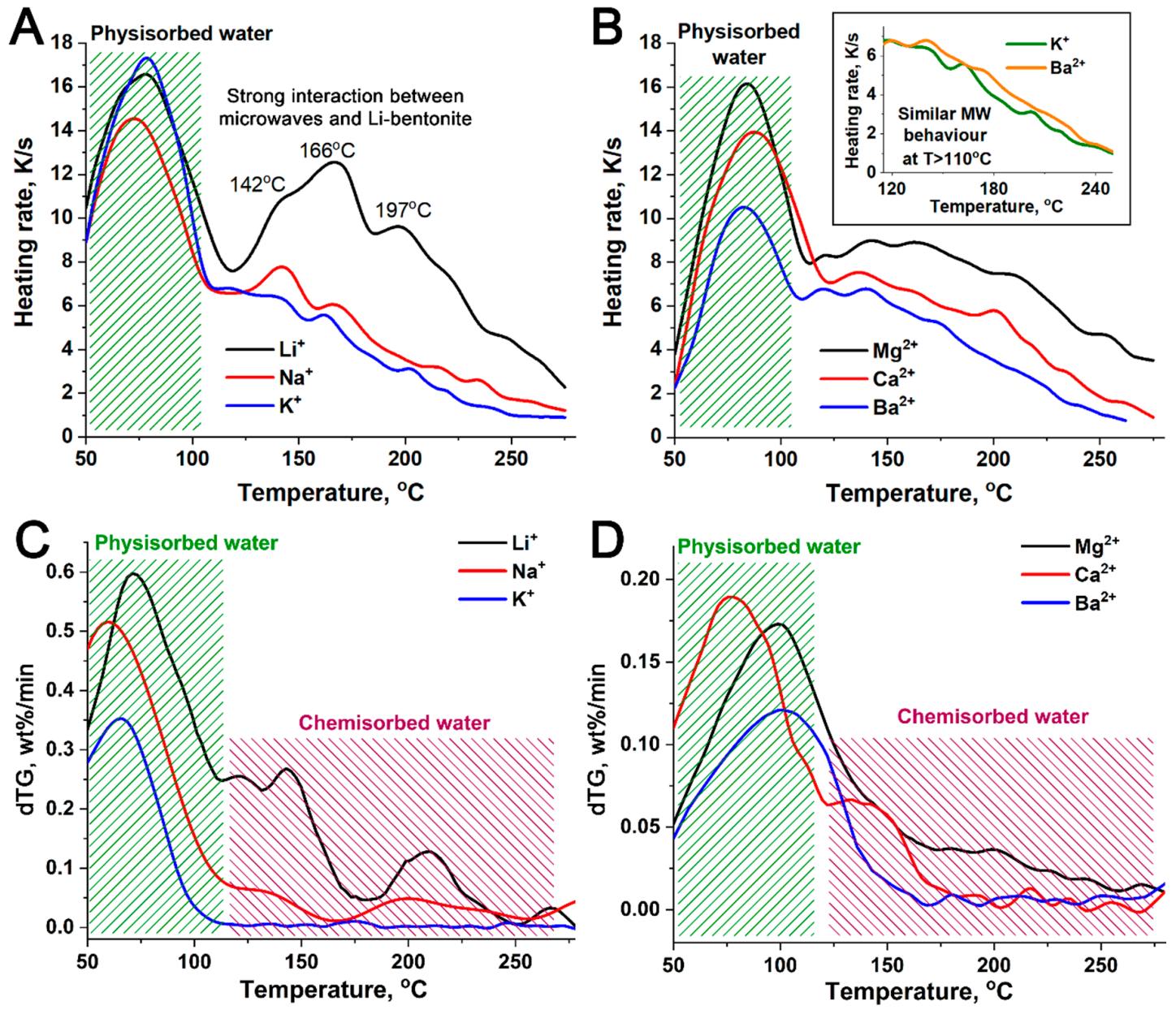

Figure 1. Comparison between the microwaves (MW) and the conventional heating rates of the bentonites: (A) MW traces of the bentonites with monovalent cations; (B) MW traces of the bentonites with divalent cations; (C) conventional dTG (derivative of thermogavimetric data, e.g., mass-loss over time) of the bentonites with monovalent cations; (D) conventional dTG of the bentonites with divalent cations.

The heating rates above $\sim 110^{\circ} \mathrm{C}$ corresponded to more complicated interactions between the materials and MWs. Among the monovalent cations, K-bentonite exhibited the weakest interaction with MWs, showing low heating rates at $\mathrm{T}>110{ }^{\circ} \mathrm{C}$ (Figure $1 \mathrm{~A}$, blue line). The most substantial interaction of the materials with MWs was detected for Li-bentonite with pronounced signals at $142{ }^{\circ} \mathrm{C}$, $166^{\circ} \mathrm{C}$ and $197^{\circ} \mathrm{C}$ (Figure 1A, black line). Probably, these signals were associated with the forms of water released from clays at $122{ }^{\circ} \mathrm{C}, 144^{\circ} \mathrm{C}$ and $208^{\circ} \mathrm{C}$, respectively, during conventional heating (Figure 1C, black line). A significant MW activity of Li-bentonite allowed this sample to reach $280{ }^{\circ} \mathrm{C}$ in $34 \mathrm{~s}$ compared to $87 \mathrm{~s}$ for K-bentonite during MW heating (Figure S2). In the case of the divalent cations, the fastest heating rates were found for $\mathrm{Mg}$-bentonite (Figure $1 \mathrm{~B}$, black line), while Ca-bentonite (Figure 1B, red line) was more active than Ba-samples (Figure 1B, blue line). The overall MW activity reduced in the order of $\mathrm{Li}^{+}>\mathrm{Na}^{+}>\mathrm{K}^{+}$and $\mathrm{Mg}^{2+}>\mathrm{Ca}^{2+}>\mathrm{Ba}^{2+}$, in a correlation with the polarisation ability of the ions. 
Interestingly, the metal cations that demonstrated the lowest heating rate at $\mathrm{T}>110^{\circ} \mathrm{C}$ (potassium and barium bentonites) had similar MW behaviour, regardless of their differences in chemical properties (Figure 1B, insertion). This observation implied that this MW-heating profile represented the heating of the core bentonite framework. The TGA (Figure 1C,D) showed that significant MW peaks corresponded to the temperature range of the release of the chemisorbed water.

Based on the obtained data, we believe that the major component which makes the most considerable impact on the MW activity of clays at high temperatures is water binding to the cation or clay framework. If the cation-water interaction is small, then the MW activity (e.g., heating rates) is mainly determined by the nature of the clay mineral. In such a way, similar MW behaviour of Kand Ba-bentonites (Figure 1B, insertion) could be due to the minimised impact of the cation-water interaction and therefore predetermined by the clay nature. This assumption can guarantee almost the identical MW activities of the samples.

Further analysis of the MW-bentonite interactions was carried out via the deconvolution of the MW traces by Gaussians (Figure 2). This procedure was done to achieve a correlation of $>0.95$ based on a minimal number of Gaussians, which was found to be six. Figure 2A shows deconvolution results for the Li-bentonite (Figure 2A), and the rest of the samples can be found in Figure S3. The first signal (Figure 2A) was associated with physisorbed water, while the rest corresponded to more comprehensive interactions and required more detailed analysis. For simplification, the bentonites were separated into the monovalent and divalent groups, and each Gaussian peak signal (numbered from one to six) was compared among the other samples within the groups. Figure $2 \mathrm{~B}$ demonstrates an example of such analysis for the 2 nd peak in the case of the monovalent cations. As it is seen from Figure $2 \mathrm{~B}$, the dependence between the heating rate maximum amd the corresponding temperature forms a straight line. A similar linear dependency was found for the third and fourth Gaussians (Figure 2C), while both fifth and sixth signals were distributed more randomly. Based on the correlation between MW traces and dTG data (Figure 1), we assume that the second, third and fourth peaks corresponded to the three discrete types of water within the bentonite which are well-described in the literature [24]. Furthermore, similar linear relationships between the dTG peak intensity and the energy of the water-clay interaction (dTG peak position) were found during conventional heating and were dependent on the type of exchangeable cation [25]. The more comprehensive fifth and sixth Gaussians could depend on the surface morphology, which is different for the various exchangeable cations.

It can be graphically seen from Figure 2C, where the lines (for second, third and fourth signals) had a common point. For the mathematically correct identification of the coordinates of this point, all five lines on Figure 2C were described using linear equation Rate $_{\text {max }}=$ Intercept $_{\text {peak }}+\operatorname{tg} \alpha_{\text {peak }} \cdot T$. Then, a graph Intercept $_{\text {peak }}=f\left(\operatorname{tg} \alpha_{\text {peak }}\right)$ was placed (Figure 2D) and described as Intercept $t_{\text {peak }}=0.24+107 \cdot \operatorname{tg} \alpha_{\text {peak }}$.

We assume the common temperature for all cations heating rate points (Figure $2 \mathrm{C}$ ) could have a simple physical meaning. The temperature of $107^{\circ} \mathrm{C}$ stood for the temperature for the removal of the internal water, so at this temperature, there was no bound water left. In contrast, the surface-coordinated water at these conditions firmly bound, could not be moved and did not interact with MW. In this case, $0.24 \mathrm{Ks}^{-1}$ is the MW-heating rate of the clay framework at $300 \mathrm{~W}$ power (our experimental conditions).

The data achieved on the MW activities of $\mathrm{Li}^{-}, \mathrm{Na}^{-}, \mathrm{K}^{-}, \mathrm{Mg}^{-}, \mathrm{Ca}^{-}$and Ba-bentonites let us design an experiment to increase the amount of bio-oil during the MW-assisted pyrolysis of cellulose. The experimental setup is shown in Figure 3.

A layer of the relevant bentonite $(0.5 \mathrm{~g})$ was packed underneath $1 \mathrm{~g}$ of cellulose in a Teflon vessel with a $10 \mathrm{~mL}$ volume (Figure 3). Such a "layered" technique was previously reported to increase the yield of the bio-oil to $\sim 15 \%$ due to additional production of water from bentonite during heating [1]. The vessel of $10 \mathrm{~mL}$ was placed inside a $35 \mathrm{~mL}$ glass vessel, which was full of the relevant bentonite for the intensification of the heating effect through conventional heating. Such an experimental scheme made it possible to exploit the bentonite in the $35 \mathrm{~mL}$ vessel many times until it was damaged by MWs [26], while the cellulose could be mechanically separated from the bentonite layer in the $10 \mathrm{~mL}$ vessel. 

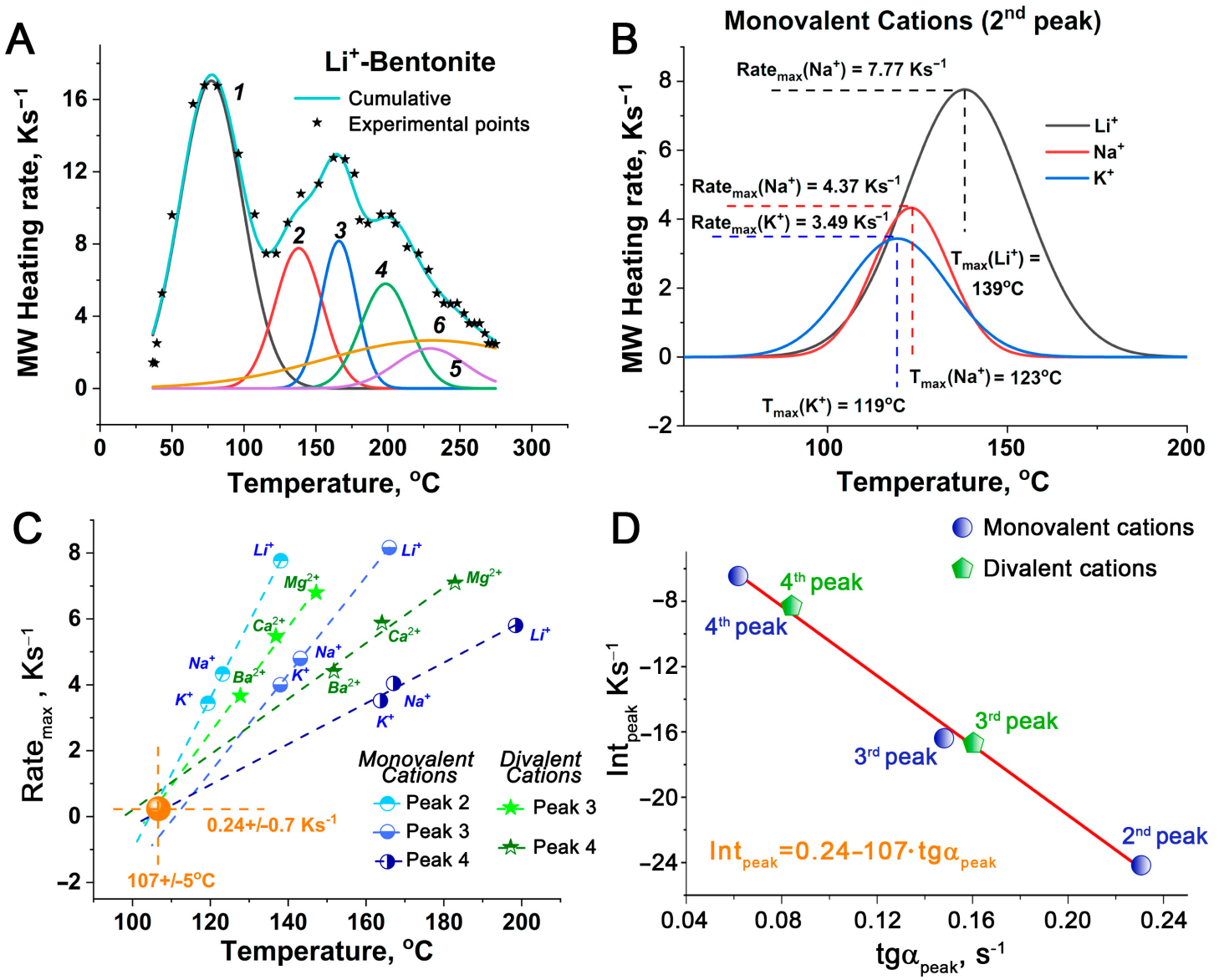

Figure 2. Analysis of MW traces: (A) example of MW-trace deconvolution by Gaussians; (B) example of the analysis of the Gaussians; (C) linear dependencies between the maximum MW heating rates of the Gaussians and their temperatures; (D) a graph, representing Intercept $_{\text {peak }}=f\left(\operatorname{tg} \alpha_{\text {peak }}\right)$.

Table 1 shows the yields of bio-oil during the noncatalytic pyrolysis of cellulose depending on the type of exchangeable cation within the bentonite. As it is seen from Table 1, the application of bentonite as an additional heater and a source for water production during the MW pyrolysis of cellulose allowed us to increase the yield of bio-oil. The amount of bio-oil for pure cellulose was $11.7 \mathrm{wt.} \%$, which was extended to $18.8 \mathrm{wt} . \%$ in the presence of Li-bentonite. Interestingly, the bio-oil yield increased in the order of $\mathrm{Li}^{+}>\mathrm{Na}^{+}>\mathrm{K}^{+}$and $\mathrm{Mg}^{2+}>\mathrm{Ca}^{2+}>\mathrm{Ba}^{2+}$, repeating the previously observed dependencies for the MW activities of bentonites. This observation proved the effect of conventional heating rate of the MW-active clay, promoting faster pyrolysis rates and consequently increasing bio-oil yields. The heat flow and the pyrolysis time were good enough to pass the heat, even through the walls of the Teflon vessel, which has a low coefficient of temperature conductivity.

The composition of the collected bio-oils was examined using the GC-FID (gas chromatography coupled with flame ionization detector) method. Figure 4 shows the GC-FID spectra of the bio-oils collected for the pure cellulose experiment (Figure 4, top) and the cellulose with Li-bentonite (Figure 4, bottom). The presence of Li-bentonite improved the quality of the bio-oil, enhancing the yield of levoglucosan, which is a primary intermediate during cellulose pyrolysis [27]. Its yield was increased from $3.9 \mathrm{wt} . \%$ to $7.4 \mathrm{wt} . \%$ without any catalytic effect of the clay mineral, providing $33.33 \%$ and $39.36 \%$ of selectivity from the bio-oils, respectively (Table 1). We believe there is no catalytic effect of the clay mineral or $\mathrm{Li}^{+}$ions due to its placed underneath the cellulose. This approach is substantially different from the methodology applied previously, which involved a direct mixing of cellulose with the catalyst and therefore could cause the reduction of levoglucosan [28]. The improvement of the levoglucosan 
yields could result in the increased amount of the bio-oil (Table 1) as well as a partial capturing of levoglucosan by the vapour produced by the bentonite underneath cellulose. Such a capturing process could prevent levoglucosan decomposition to smaller chemicals (including levoglucosenone), which proceeds as a secondary reaction in a vapour phase [29]. This assumption is well supported by the reduction of levoglucosenone yield in the presence of Li-doped bentonite (Figure 4). The experiment has been done for all clays. However, Li-doped bentonite demonstrated the most evident difference in bio-oil composition. We believe that this performance of Li-bentonite could be a result of its highest efficiency of interaction with MW radiation causing its highest heating rate (see Figure 2) and production of the highest amount of bio-oil (see Table 1).

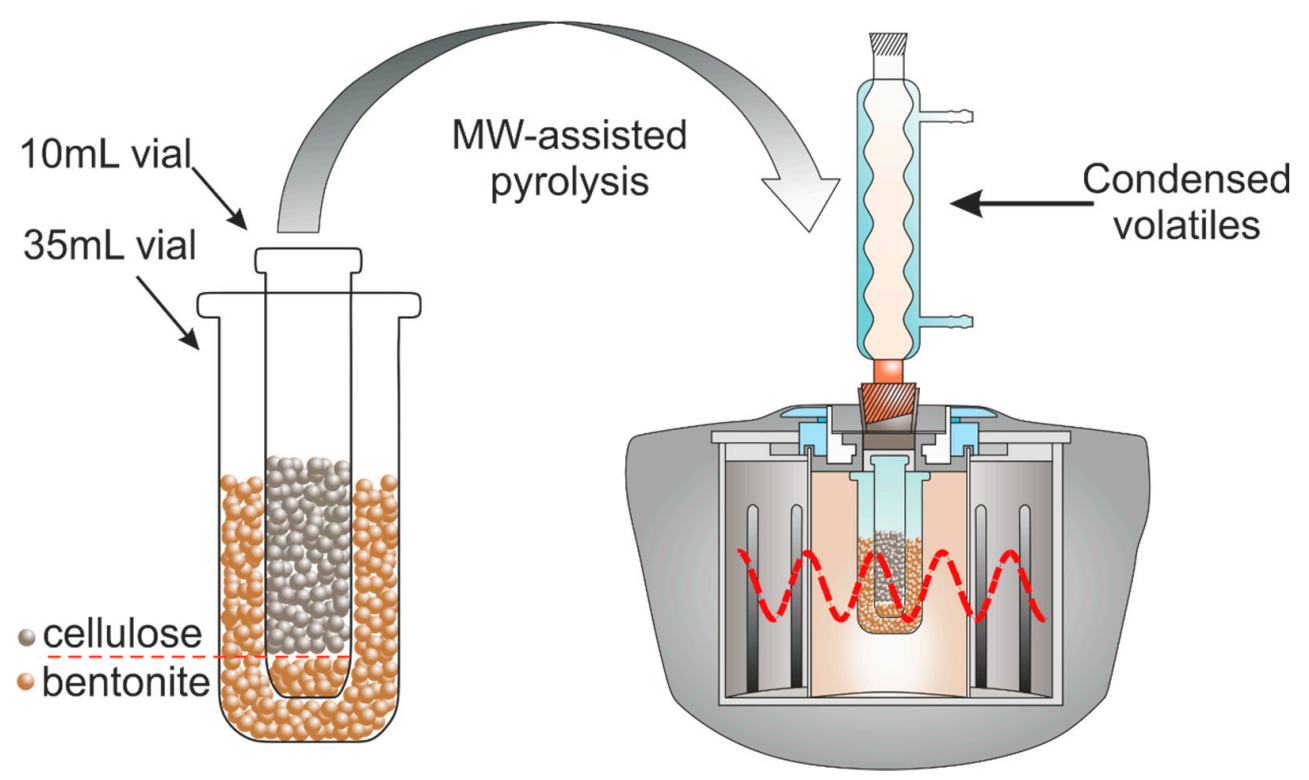

Figure 3. Experimental setup to enhance the yield of bio-oil during the MW-assisted pyrolysis of cellulose.

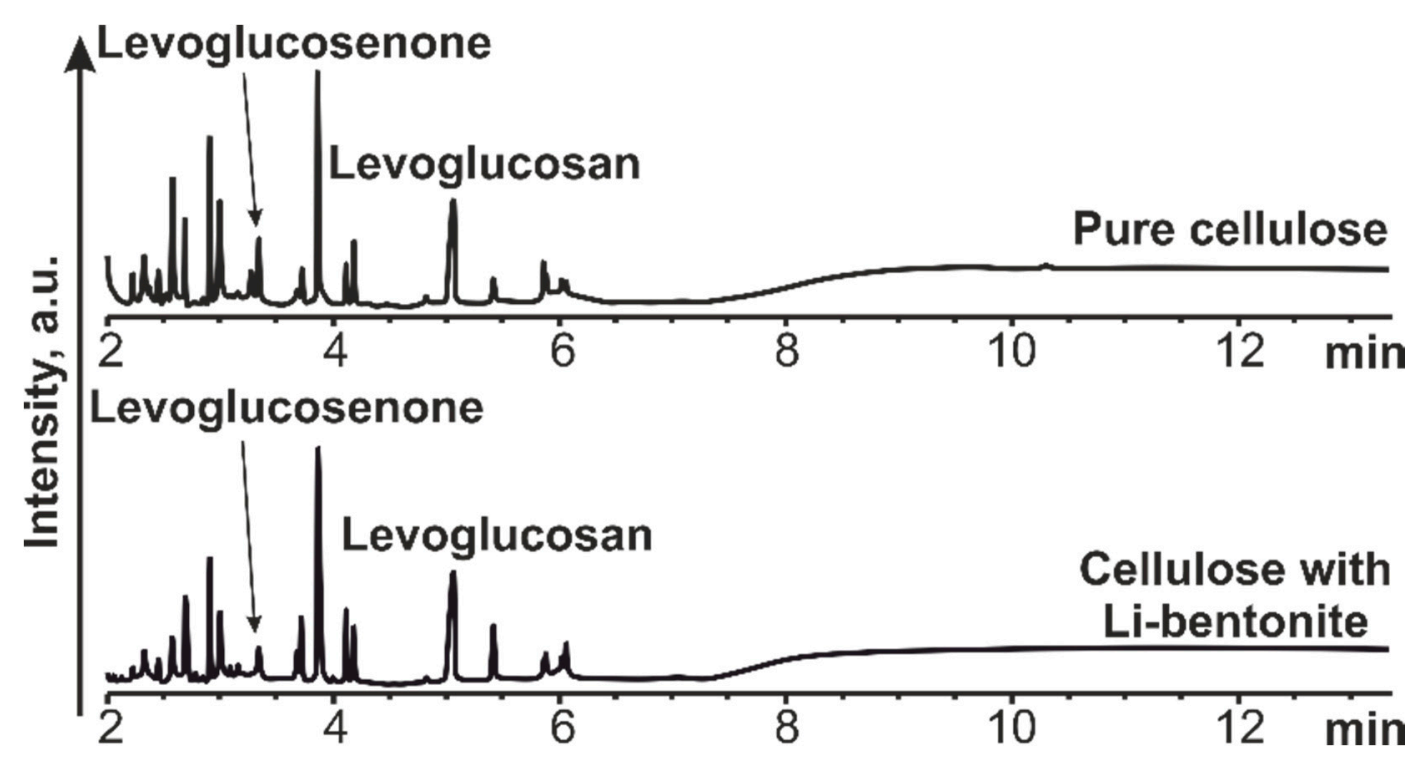

Figure 4. GC-FID spectra of the bio-oil resulted from pure cellulose MW pyrolysis (top) and cellulose MW pyrolysis in the presence of Li-bentonite (bottom). 
Table 1. Yields of the bio-oil during the MW pyrolysis of cellulose (at $280^{\circ} \mathrm{C}$ ) depending on the type of the exchangeable cation in bentonite.

\begin{tabular}{cc}
\hline Material & Bio-Oil (wt.\%) \\
\cline { 2 - 3 } Li-bentonite & 18.8 \\
Na-bentonite & 15.4 \\
K-bentonite & 12.9 \\
Mg-bentonite & 14.8 \\
Ca-bentonite & 14.3 \\
Ba-bentonite & 12.5 \\
Pure cellulose & A \\
\cline { 2 - 2 } A The MW-assisted pyrolysis of pure cellulose was conducted only in a $35 \mathrm{~mL}$ open-vessel.
\end{tabular}

\section{Conclusions}

In conclusion, we have found that bentonite activity in the MW-assisted depolymerization of cellulose depended on the presence of internal water. The intensity of this interaction was controlled by the cation nature the nature of the exchangeable cation. It reduced in the order of $\mathrm{Li}^{+}>\mathrm{Na}^{+}>\mathrm{K}^{+}$and $\mathrm{Mg}^{2+}>\mathrm{Ca}^{2+}>\mathrm{Ba}^{2+}$. These experimental dependencies correlated with the polarisation ability of the ions. The MW traces (heating rate vs. temperature) were deconvoluted by six Gaussians. Their analysis revealed a linear dependence between the maximum of the Gaussian and its temperature for both monovalent and divalent exchangeable cations. Notably, these lines had a common intercept point around $0.24 \mathrm{~K} \mathrm{~s}^{-1}$ and $107^{\circ} \mathrm{C}$, which could represent a fundamental property of clays and predict MW activity of clays, possessing a theoretical exchangeable cation with a low polarisation ability. A unique experiment was designed to employ a relatively high MW activity of the bentonites to increase the amount of bio-oil (organic fraction) during noncatalytic MW cellulose pyrolysis. The bio-oil yield increased in the order of $\mathrm{Li}^{+}>\mathrm{Na}^{+}>\mathrm{K}^{+}$and $\mathrm{Mg}^{2+}>\mathrm{Ca}^{2+}>\mathrm{Ba}^{2+}$, repeating the observed dependencies for the MW activities of bentonites. We believe that the improved yields of bio-oil are due to: (i) high MW activity of bentonites, which conventionally increased the heating rates of cellulose; and (ii) production of water by hydrophilic clay minerals, favouring depolymerisation of cellulose. The most MW-active sample among the others, Li-bentonite, gave a $37.8 \%$ increase in the organic fraction. Furthermore, this bio-oil possessed an improved quality compared to the bio-oil of pure cellulose due to higher yield and selectivity towards levoglucosan (the primary intermediate), which is also a valuable chemical platform. The suggested experimental scheme on the improvement of bio-oil yield exploits green and available bentonites, which can be used multiple times.

Supplementary Materials: The following are available online at http://www.mdpi.com/2673-4079/1/3/21/s1, Figure S1: (A) XRD analysis of the original bentonite; (B) thermal analysis of the original bentonite, Figure S2: Integrated forms of MW traces, showing that Li-bentonite reached $280^{\circ} \mathrm{C}$ in $34 \mathrm{~s}$ while $\mathrm{K}$-bentonite reached $280{ }^{\circ} \mathrm{C}$ in 87 s, Figure S3: Gaussian deconvolution of the MW traces: (A) Li-bentonite; (B) Na-bentonite; (C) K-bentonite; (D) Mg-bentonite; (E) Ca-bentonite; (F) Ba-bentonite. Notably, as it is seen the 2nd peaks of divalent cations-samples were exceptional and excluded from the analysis (main paper body, Figure $2 \mathrm{C}, \mathrm{D}$ ) due to its strong overlapping with physisorbed water.

Author Contributions: A.D. has conducted all the experiments. The data processing was done by A.D. and V.B. The discussion of the results was carried out by A.D., I.P., S.G., J.C. and V.B. All authors were involved in the preparation of this scientific manuscript. All authors have read and agreed to the published version of the manuscript.

Funding: This research received no external funding.

Acknowledgments: The authors acknowledge the financial support of the University of York based on Overseas Research Scholarship. In addition, the authors appreciate the assistance of Artem Kostiyuk on mathematical data processing.

Conflicts of Interest: The authors declare no conflict of interest. 


\section{Appendix A}

Microcrystalline cellulose was supplied by Sigma-Aldrich (UK). Na-bentonite and the saltls ( $\mathrm{LiCl}, \mathrm{NaCl}, \mathrm{KCl}, \mathrm{MgCl}_{2}, \mathrm{CaCl}_{2}$ and $\mathrm{BaCl}_{2}$ ) were supplied by Fischer Scientific (UK).

Small-angle XRD analysis was performed using a Bruker D8 Discover equipped with a temperaturecontrolled, bored graphite rod furnace, custom-built at the University of York. Samples were filled into $1 \mathrm{~mm}$ o/d glass capillaries. The radiation source was a microfocus source using $\mathrm{CuK} \alpha$ radiation at $\lambda=1.5406 \AA$, which was trimmed using a $1 \mathrm{~mm}$ circular slot and a $0.5 \mathrm{~mm}$ collimator. Diffraction patterns were collected as a function of temperature using a Bruker Vantec 500 detector positioned on the goniometer to allow data to be collected between 3.9 and $110 \AA$. The instrument was calibrated using Silver Behenate. The data were processed using Bruker DIFFRAC. SUITE EVA software. Samples were acquired for $900 \mathrm{~s}$ per scan and equilibrated for $20 \mathrm{~s}$ at each temperature interval.

The thermal analysis was performed in $\mathrm{N}_{2}$ flow conditions $\left(60 \mathrm{~mL} \mathrm{~min}^{-1}\right)$ using Stanton Redcroft STA625 Thermal Analysis at the temperature range between ambient and $500{ }^{\circ} \mathrm{C}$ and a heating rate of $10{ }^{\circ} \mathrm{C} \mathrm{min}{ }^{-1}$. The mass of the samples for the analysis was $10 \pm 0.2 \mathrm{mg}$ accuracy.

The first step during the cation-exchange procedure was to prepare $4 \mathrm{wt} . \%$ suspension of bentonite in water during intensive stirring for $24 \mathrm{~h}$. This original bentonite contained sodium as a counterion. The exchanging process involved dropwise addition of the relevant salt solution (including $\mathrm{NaCl}$ for comparison) at a $0.5 \mathrm{M}$ concentration to the swollen bentonite with intense stirring. The ratio between the bentonite suspension and the salt was 1:1. Finally, the samples were centrifuged at $3500 \mathrm{rpm}$ for $10 \mathrm{~min}$, and the aqueous solution was removed with decantation. It was proved, based on the ICP (inductively coupled plasma) analysis of washing water, that the exchange procedure for the substitution of $\mathrm{Na}^{+}$cation toward specific cations had to be repeated at least eight times. After the last exchange step, the samples were washed from the excess of anions. The addition of distilled water during magnetic stirring was followed by the centrifugation and subsequent decantation of the aqueous phase. This procedure was repeated until a negative reaction for $\mathrm{Cl}^{-}$anions, which was checked by adding $\mathrm{Ag}^{+}$to the solution. After the cation-exchange procedure, the samples were dried at $105{ }^{\circ} \mathrm{C}$. All the samples ( $\mathrm{Li}-, \mathrm{Na}, \mathrm{K}-, \mathrm{Mg}-, \mathrm{Ca}-$ and Ba-bentonites) were stored in the bottles sealed with a parafilm to minimise their interaction with the air.

The MW experiments were carried out in a CEM Discover Microwave reactor. Research on the bentonites $(1 \mathrm{~g})$ behaviour in an MW was done in $10 \mathrm{~mL}$ closed vessels. The study on cellulose pyrolysis was done in an open vessel with a condenser at the top, using $1 \mathrm{~g}$ of cellulose. An infrared temperature detector at the bottom of the vessel allowed monitoring MW pyrolysis temperature in time. The reactor worked in a fixed power mode $(300 \mathrm{~W})$ to reach the target temperature of $280^{\circ} \mathrm{C}$, which was substantially higher than the temperature of MW-assisted pyrolysis of microcrystalline cellulose, which happened at $180^{\circ} \mathrm{C}$.

The Gaussian deconvolution was done using Origin 2018 software by the means of "Multiple Peak Fit". The Gaussian deconvolution was tested, starting from more than three peaks to describe the MW traces with a minimal number of Gaussians to get a $>0.95$ correlation fit with the experimental signal. Such a fit was achieved in the case of six Gaussians.

The collected bio-oil was washed from both the condenser and the MW vessel with $30 \mathrm{~mL}$ of acetone. An aliquot of $20 \mathrm{~mL}$ was taken for the evapouration at $105^{\circ} \mathrm{C}$ for $6 \mathrm{~h}$ in a ceramic dish (weighted in advance). Then, the ceramic dish was weighted together with the left organic residue. The difference between the masses of the ceramic dish with and without organic residue was accepted as the yield of organic fraction of bio-oil (tar).

Qualitative and quantitative analysis of the bio-oil was done by the GC-FID method, using an Agilent Technologies 6890 A with Rxi-5HT column. The gas chromatography program ramped the temperature from $50{ }^{\circ} \mathrm{C}$ to $300{ }^{\circ} \mathrm{C}$ at $30{ }^{\circ} \mathrm{C} / \mathrm{min}$ followed by a hold at $300{ }^{\circ} \mathrm{C}$ for $5 \mathrm{~min}$. A split ratio was established at 5:1. The quantification procedure was based on the calibration curve of the relevant references. 


\section{References}

1. Doroshenko, A.; Pylypenko, I.; Heaton, K.; Cowling, S.; Clark, J.; Budarin, V. Selective Microwave-Assisted Pyrolysis of Cellulose towards Levoglucosenone with Clay Catalysts. ChemSusChem 2019, 12, 5224-5227. [CrossRef] [PubMed]

2. Ye, J.; Jiang, J.; Xu, J. Effect of Alcohols on Simultaneous Bio-oil Upgrading and Separation of High Value-added Chemicals. Waste Biomass Valorization 2017, 9, 1779-1785. [CrossRef]

3. Watson, M.J. Platinum Group Metal Catalysed Hydrodeoxygenation of Model Bio-oil Compounds. Johns. Matthey Technol. Rev. 2014, 58, 156-161. [CrossRef]

4. Gunawan, R.; Li, X.; Lievens, C.; Gholizadeh, M.; Chaiwat, W.; Hu, X.; Mourant, D.; Bromly, J.; Li, C.-Z. Upgrading of bio-oil into advanced biofuels and chemicals. Part I. Transformation of GC-detectable light species during the hydrotreatment of bio-oil using Pd/C catalyst. Fuel 2013, 111, 709-717. [CrossRef]

5. Vispute, T.P.; Zhang, H.; Sanna, A.; Xiao, R.; Huber, G.W. Renewable Chemical Commodity Feedstocks from Integrated Catalytic Processing of Pyrolysis Oils. Science 2010, 330, 1222-1227. [CrossRef]

6. Bridgwater, A. Principles and practice of biomass fast pyrolysis processes for liquids. J. Anal. Appl. Pyrolysis 1999, 51, 3-22. [CrossRef]

7. Álvarez-Chávez, B.J.; Godbout, S.; Le Roux, É.; Palacios, J.H.; Raghavan, V. Bio-oil yield and quality enhancement through fast pyrolysis and fractional condensation concepts. Biofuel Res. J. 2019, 6, 1054-1064. [CrossRef]

8. Khan, A.S.; Man, Z.; Bustam, M.A.; Kait, C.F.; Khan, M.I.; Muhammad, N.; Nasrullah, A.; Ullah, Z.; Ahmad, P. Impact of Ball-Milling Pretreatment on Pyrolysis Behavior and Kinetics of Crystalline Cellulose. Waste Biomass Valorization 2015, 7, 571-581. [CrossRef]

9. Karnjanakom, S.; Asep, B.; Hao, X.; Yang, J.; Samart, C.; Abudula, A.; Guan, G.; Du, X. A green method to increase yield and quality of bio-oil: Ultrasonic pretreatment of biomass and catalytic upgrading of bio-oil over metal (Cu, Fe and/or Zn)/?-Al ${ }_{2} \mathrm{O} 4$. RSC Adv. 2015, 5, 83494-83503. [CrossRef]

10. Gumaling, R.P.; Agusan, J.R.; Ellacer, N.V.C.R.; Abi, G.M.T.A.; Pajaron, J.R.P.; Joyno, J.R.Q.; Joyno, C.Q.; Ido, A.L.; Arazo, R.O. Increased bio-oil yield from Swietenia macrophylla seeds through microwave pretreatment and ultrasonic-assisted solvent extraction. Sustain. Environ. Res. 2018, 28, 430-437. [CrossRef]

11. Doroshenko, A.; Budarin, V.L.; McElroy, C.R.; Hunt, A.J.; Rylott, E.; Anderson, C.W.; Waterland, M.; Clark, J.H. Using in vivo nickel to direct the pyrolysis of hyperaccumulator plant biomass. Green Chem. 2019, 21, 1236-1240. [CrossRef]

12. Budarin, V.L.; Clark, J.H.; Lanigan, B.A.; Shuttleworth, P.; Breeden, S.W.; Wilson, A.J.; MacQuarrie, D.J.; Milkowski, K.; Jones, J.; Bridgeman, T.; et al. The preparation of high-grade bio-oils through the controlled, low temperature microwave activation of wheat straw. Bioresour. Technol. 2009, 100, 6064-6068. [CrossRef]

13. Budarin, V.L.; Clark, J.H.; Lanigan, B.A.; Shuttleworth, P.; MacQuarrie, D.J. Microwave assisted decomposition of cellulose: A new thermochemical route for biomass exploitation. Bioresour. Technol. 2010, 101, 3776-3779. [CrossRef] [PubMed]

14. Budarin, V.L.; Zhao, Y.; Gronnow, M.J.; Shuttleworth, P.S.; Breeden, S.W.; MacQuarrie, D.J.; Clark, J.H. Microwave-mediated pyrolysis of macro-algae. Green Chem. 2011, 13, 2330-2333. [CrossRef]

15. Mishra, R.R.; Sharma, A.K. Microwave-material interaction phenomena: Heating mechanisms, challenges and opportunities in material processing. Compos. Part A Appl. Sci. Manuf. 2016, 81, 78-97. [CrossRef]

16. Fan, J.; Shuttleworth, P.S.; Gronnow, M.J.; Breeden, S.W.; Clark, J.H.; MacQuarrie, D.J.; Budarin, V.L. Influence of Density on Microwave Pyrolysis of Cellulose. ACS Sustain. Chem. Eng. 2018, 6, 2916-2920. [CrossRef]

17. Doroshenko, D.; Pylypenko, I.; Kovalchuk, I.; Kornilovych, B.; Spasonova, L. Investigation of the structure and sorption peculiarities of cobalt and uranium ions by nanocomposites based on montmorillonite and tetraethoxysilane. East. Eur. J. Enterp. Technol. 2018, 5, 6-11. [CrossRef]

18. Pylypenko, I.V.; Spasonova, L.M. Removal of chromium (VI) from water solutions by means of composites based on montmorillonite and iron oxide. Vopr. Khimii Khimicheskoi Tekhnologii 2020, 2020, 121-127. [CrossRef]

19. Bergaya, F.; Lagaly, G. (Eds.) Handbook of Clay Science, 2nd ed.; Elsevier: Amsterdam, The Netherlands, 2013; Volume 5, ISBN 978-0-08-099364-5.

20. Sun, Z.; Park, Y.; Zheng, S.; Ayoko, G.A.; Frost, R.L. XRD, TEM, and thermal analysis of Arizona Ca-montmorillonites modified with didodecyldimethylammonium bromide. J. Colloid Interface Sci. 2013, 408, 75-81. [CrossRef] 
21. Bergaya, F.; Lagaly, G. (Eds.) Developments in Clay Science. In Handbook of Clay Science, 2nd ed.; Elsevier: Amsterdam, The Netherlands, 2013; Volume 5, ISBN 978-0-08-099364-5.

22. Vorhauer, N.; Tretau, A.; Bück, A.; Prat, M. Microwave drying of wet clay with intermittent heating. Dry. Technol. 2019, 37, 664-678. [CrossRef]

23. McCallister, D.L. Microwave Drying of Clays for X-ray Diffraction Analysis. Soil Sci. Soc. Am. J. 1986, 50, 807-809. [CrossRef]

24. Ammar, M.; Oueslati, W.; Ben Rhaiem, H.; Amara, A.B.H. Quantitative XRD analysis of the dehydration-hydration performance of $\left(\mathrm{Na}^{+}, \mathrm{Cs}^{+}\right)$exchanged smectite. Desalin. Water Treat. 2013, 52, 4314-4333. [CrossRef]

25. Guindy, N.M.; El-Akkad, T.M.; Flex, N.S.; El-Massry, S.R.; Nashed, S. Thermal Dehydration of Mono- and Divalnt Montmorillonite Cationoc Derivatives. Thermochim. Acta 1985, 88, 369-378. [CrossRef]

26. Kowalski, S.J.; Banaszak, J.; Rybicki, A. Damage analysis of microwave-dried materials. AIChE J. 2011, 58, 2097-2104. [CrossRef]

27. Shafizadeh, F. Pyrolysis and Combustion of Cellulosic Materials. Adv. Carbohydr. Chem. 1968, 23, 419-474. [CrossRef]

28. Iwamoto, M.; Shimatai, A.; Honda, M.; Matsukata, M. Depolymerization of Cellulose with Superheated Steam: Remarkable Obstruction Effects of Sodium and High Reactivity of Crystalline Cellulose. ACS Sustain. Chem. Eng. 2018, 6, 6570-6576. [CrossRef]

29. Zhu, C.; Maduskar, S.; Paulsen, A.D.; Dauenhauer, P.J. Alkaline-Earth-Metal-Catalyzed Thin-Film Pyrolysis of Cellulose. ChemCatChem 2016, 8, 818-829. [CrossRef]

Publisher's Note: MDPI stays neutral with regard to jurisdictional claims in published maps and institutional affiliations.

(C) 2020 by the authors. Licensee MDPI, Basel, Switzerland. This article is an open access article distributed under the terms and conditions of the Creative Commons Attribution (CC BY) license (http://creativecommons.org/licenses/by/4.0/). 